\title{
Nossa vida após o câncer de mama: percepções e repercussões sob o olhar do casal
}

Our life after breast cancer: perceptions and repercussions from the perspective of the couple Nuestra vida después del cáncer de mama: percepciones y repercusiones desde la perspectiva de la pareja

\section{Dayane de Barros Ferreira', Priscila Moreira Farago', Paula Elaine Diniz dos Reis", Silvana Schwerz Funghetto"}

' Bacharel em Enfermagem pelo Centro Universitário UNIEURO. Brasília-DF, Brasil.

"Universidade de Brasília (UnB). Departamento de Enfermagem. Brasília-DF, Brasil.

RESUMO

Trata-se de estudo qualitativo, realizado no Ambulatório de Mastologia de um hospital público do Distrito Federal, com o qual se objetivou conhecer as repercussões do câncer de mama na vida de casais, mulheres mastectomizadas e seus companheiros. A amostra foi constituída por três casais, três companheiros e cinco mulheres mastectomizadas. Foram realizadas entrevistas semiestruturadas, das quais emergiram duas grandes categorias: Percepções acerca do câncer de mama e Repercussões na vida cotidiana. O diagnóstico de câncer é recebido de forma traumática, trazendo sentimentos de mutilação, dependência, preconceito e perda da feminilidade. Conclui-se que ocorrem mudanças significativas na vida do casal e que o apoio mútuo é necessário para um melhor enfrentamento da patologia, seguido pelo amparo familiar.

Descritores: Saúde da mulher; Câncer de mama; Mastectomia.

\section{ABSTRACT}

This is a qualitative study, conducted at a Clinic of Mastology of a public hospital of the Federal District, which aimed to know the impact of breast cancer in the lives of couples, women submitted to mastectomy and their partners. The sample consisted of three couples, five women submitted to mastectomy and three partners. Semi-structured interviews were conducted, which gave rise to two broad categories: Perceptions about breast cancer and Consequences in everyday life. The diagnosis of cancer is received as a traumatic one, bringing feelings of mutilation, dependence, prejudice and loss of femininity. One conclude that significant changes occur in married life and that mutual support is needed to better cope with the disease, followed by the necessary family support.

Key words: Women's health; Breast cancer; Mastectomy.

\section{RESUMEN}

Este es un estudio cualitativo, realizado en una Clínica de Mastología de un hospital público del Distrito Federal, cuyo objetivo fue conocer el impacto del cáncer de mama en la vida de las parejas, mujeres sometidas a mastectomía y sus compañeros. La muestra constó de tres parejas, cinco mujeres sometidas a mastectomía y tres compañeros. Entrevistas semiestructuradas se llevaron a cabo, lo que dio lugar a dos grandes categorías: Percepciones sobre el cáncer de mama y Repercusiones en la vida cotidiana. El diagnóstico de cáncer es recibido como de forma traumática, con sentimientos de mutilación, dependencia, preconceptos y pérdida de la feminidad. Es posible concluir que se producen cambios significativos en la vida de la pareja y que el apoyo mutuo es necesario para sobrellevar mejor la enfermedad, seguido por el necesario apoyo familiar.

Palabras clave: Salud de la mujer; Cáncer de mama; Mastectomía. 


\section{INTRODUÇÃO}

O câncer é a segunda causa de morte por doença no Brasil. As estimativas atuais apontam que ocorrerão 466.730 casos novos da doença, sendo que a incidência prevista entre as mulheres é de 235 mil, sendo o câncer de mama a patologia de maior destaque ${ }^{(1-2)}$.

Dentre as modalidades terapêuticas para o câncer de mama, a cirurgia é ainda o principal recurso utilizado para desempenhar a função de controle e erradicação da doença. Porém, a mastectomia tem em si um caráter agressivo e traumatizante para a vida e saúde da mulher, pois interfere não só na imagem corporal, mas na vida sexual, com perda funcional que implica em limitações laborais, alterações psíquicas, emocionais e sociais, associadas à depressão e ansiedade ${ }^{(1,3)}$.

Além disso, a paciente vivencia, ao longo do tratamento, perdas e sintomas adversos, acarretando incertezas quanto ao futuro, podendo incorrer em efeitos traumáticos que vão além da própria enfermidade, pois a mulher se depara com a iminência da perda de um órgão cheio de representações, assim como o temor de ter uma doença sem cura e suas repercussões ${ }^{(4)}$.

O impacto da doença também acomete o companheiro dessas mulheres que, em geral, se surpreende com tal diagnóstico, visto que tem a visão de que as mulheres possuem um melhor autocuidado, principalmente no que concerne à realização de exames preventivos, o que deveria automaticamente refutar qualquer hipótese de doença. Os companheiros manifestam desesperança, impotência, intranqüilidade e medo do óbito das esposas, porém possuem a tendência de manter o pensamento positivo em relação às perspectivas prognósticas ${ }^{(5)}$.

Há escassez de estudos que abordem a vivência do casal frente ao câncer de mama feminino, havendo a necessidade de outras pesquisas que facilitem a compreensão de tal situação(5).

Como referencial teórico, partiu-se do determinante de que qualquer doença enseja o afloramento de um conjunto de sentimentos que implicarão diretamente em seu prognóstico e na forma como o indivíduo vai reestruturar aspectos importantes de sua vida. O câncer de mama faz com que a mulher vivencie três etapas importantes, as quais se sobrepõem, a saber: o recebimento do diagnóstico, que é geralmente sentido como algo de natureza negativa; a realização de um tratamento longo e agressivo; e a aceitação de um corpo marcado por uma nova imagem, cuja alteração poderá ter uma necessidade de aceitação e de convivência com a mesma ${ }^{(6-7)}$.

Assim, a partir de vivências em campo de estágio durante a graduação e da revisão de literatura sobre o tema proposto, surgiu o desejo de conhecer quais são as repercussões do câncer de mama em casais, mulheres mastectomizadas e seus companheiros em relação ao impacto de várias alterações no âmbito físico, emocional e social que surgem após o diagnóstico, o que culminou no objetivo principal deste estudo.

\section{METODOLOGIA}

Trata-se de um estudo qualitativo, que se baseia no pressuposto de que o conhecimento sobre os indivíduos só é possível com a descrição da experiência humana, tal como ela é vivida e definida pelas próprias pessoas ${ }^{(1)}$.

A coleta de dados foi realizada no Ambulatório de Mastologia de um hospital público de Brasília-DF, no mês de setembro de 2009, por meio de entrevistas baseadas em um roteiro semiestruturado, que foram gravadas e posteriormente analisadas. Cada participante foi convidado por meio de abordagem verbal, preservando-se sua privacidade e fazendo as entrevistas em um local reservado do hospital em questão.

Para a seleção das mulheres participantes da pesquisa, incluiu-se mulheres com idade superior a 18 anos e portadoras de câncer de mama, as quais foram submetidas à mastectomia; e excluiu-se aquelas que foram submetidas a reconstrução mamária imediatamente mastectomia.

A amostra foi composta por três casais, cinco mulheres mastectomizadas e três homens que eram companheiros de muIheres portadoras do câncer de mama e que realizaram a mastectomia. O número de sujeitos foi condicionado ao critério de redundância ou saturação dos dados, que ocorre quando as informações forem repetidas ou o acréscimo de novos dados for mínimo para submeterem-se aos procedimentos de análise ${ }^{(8)}$.

Para análise das informações emergidas das entrevistas utilizamos a Análise de Conteúdo, na modalidade temática, definida como uma técnica que consiste em apurar descrições de conteúdo aproximativas, subjetivas, para pôr em evidência a objetividade, a natureza e as forças relativas aos estímulos a que o sujeito é submetido(9).

Para que esta análise ocorra de modo sistemático, são propostas três fases distintas. A primeira, chamada de Pré-Análise, tem por objetivo a organização das idéias iniciais, levando à "elaboração de indicadores que fundamentem a interpretação final"; na segunda fase, de Exploração do Material, é realizada a decomposição do material coletado e agrupamento em unidades de significado, utilizando uma codificação específica; na terceira fase, chamada de tratamento dos resultados, deve haver a descrição e posterior interpretação das categorias evidenciadas ${ }^{(9)}$.

Assim, na primeira fase, após a transcrição das entrevistas, realizou-se a leitura flutuante com a finalidade de permitir que se estabelecesse contato com as respostas dos sujeitos e conhecesse o texto, para que então pudesse verificar as primeiras impressões, as quais se consolidariam somente na última etapa.

$\mathrm{Na}$ fase de organização e exploração do material fez-se a codificação das entrevistas, identificando os sujeitos pelas denominações de casal, homem e mulher. Nesse momento, após várias leituras, retiraram-se do texto palavras, frases ou parágrafos que apresentassem coerência com os objetivos do estudo e possibilitassem delinear as primeiras idéias agrupadas.

Na última fase, o reagrupamento das unidades de significado, após várias leituras e releituras, permitiu evidenciar as categorias finais: Percepções acerca do câncer de mama e Repercussões na vida cotidiana.

Este estudo foi realizado perante aquiescência do paciente, mediante assinatura espontânea do Termo de Consentimento Livre e Esclarecido, respeitando os princípios da Resolução $n^{\circ}$ $196 / 96$, no que se refere a pesquisas com seres humanos ${ }^{(10)}$, após ser aprovado pelo Comitê de Ética em Pesquisa do Distrito Federal, Protocolo $n^{\circ}$ 208/2009. 


\section{RESULTADOS E DISCUSSÃO}

\section{Caracterização da amostra}

Os participantes deste estudo possuíam idade entre 36 a 64 anos de idade, tanto para os homens como para as mulheres. Já o tempo de união estava em torno de 24 anos. Conforme já elucidado, coletaram-se dados de casais, companheiros ou maridos de mulheres mastectomizadas e de mulheres submetidas à mastectomia. A identificação dos sujeitos, idade e tempo de união se encontram no Quadro 1.

As falas dos participantes, que serão aqui demonstradas, estão relacionadas às repercussões do diagnóstico do câncer de mama na vida desses sujeitos, em que os mesmos citaram a perda do cabelo e a retirada da mama como as principais alterações relacionadas ao físico; já no âmbito emocional esses sujeitos manifestaram fragilidade frente a sentimentos que vão desde o medo da morte até o de se tornarem dependentes. Foram enfatizadas também as dificuldades financeiras associadas ao custo do tratamento e ao fato de sofrer preconceito como uma alteração do aspecto social. Na tentativa de amenizar tais questões, o apoio mútuo entre o casal, apoio familiar e amparo divino foram tidos como pontos essenciais.

A seguir são apresentadas as duas principais categorias que emergiram das unidades de significado contempladas durante a análise de dados, a saber, Percepções acerca do câncer de mama e Repercussões na vida cotidiana.

\section{PERCEPÇÕES ACERCA DO CÂNCER DE MAMA}

\section{Impacto do Diagnóstico}

Com relação a essa sub-categoria, observou-se que o impacto do diagnóstico de câncer de mama nas mulheres estava relacionado ao temor da morte e de se tornar um ser dependente do outro.

Meu maior medo era de morrer, né (...). (Mulher 2)

Morrer. Deixar os meninos... (Mulher 5)
De morrer. Porque você não ta preparada pra receber uma notícia dessas, né. Porque geralmente você que ta fora ouve falar câncer, morreu de câncer, morreu de câncer... só vê isso. E quando você se depara com uma doença dessa, você pensa que vai morrer. Mas ai a gente aumenta mais a fé em Deus, crê muito em Deus, até que não é assim, as coisas não são assim que nem a gente pensa. (Mulher do Casal 3)

Eu nunca tive medo de morrer, então não posso nem falar que foi a sensação de que ia morrer. O medo era de ficar dependente, entendeu? Depender de alguma coisa, ficar dependendo dos outros. Então acho que o medo maior era esse, não de morrer. (Mulher 1)

O impacto do diagnóstico do câncer de mama geralmente implica em angústia, insegurança e preocupação com o prognóstico da doença e suas repercussões físicas, sociais e psicológicas, que abarcam a possibilidade ou não de sobrevida ${ }^{(1,11-14)}$.

Apesar da boa perspectiva prognóstica, ainda é forte a crença de que o câncer resulta em morte ${ }^{(15)}$. Este caráter estigmatizante da doença decorre das poucas chances de cura que um paciente portador de câncer de mama dispunha em tempos remotos, com a utilização de técnicas cirúrgicas mutiladoras e ausência de tratamentos adjuvantes eficazes ${ }^{(13)}$. Verificou-se, ainda, que o impacto negativo do diagnóstico pode ser exacerbado pela forma como o mesmo é comunicado pelo profissional, conforme se observa na fala a seguir:

O que me abalou mais quando eu fiz o exame e vim aqui no Hospital [...] e a doutora...que tá cuidando do meu caso. Ai quando eu cheguei aqui, ela falou assim de cara, que eu tava era com câncer maligno. Nem falou assim... sem ter piedade da gente. Ai eu fiquei muito abalada! ( $\mathrm{Mu}$ Iher do Casal 1)

Caetano et al ${ }^{(13)}$ reiteram tal afirmação quando referem que algumas pacientes revelaram não terem tido consciência do

\begin{tabular}{|c|c|c|c|c|c|c|c|c|c|c|c|}
\hline \multicolumn{12}{|c|}{ Dados da Amostra } \\
\hline \multirow[t]{2}{*}{ Variáveis } & \multicolumn{3}{|c|}{ Casais } & \multicolumn{3}{|c|}{$\begin{array}{l}\text { Companheiros / } \\
\text { Maridos de Mulheres } \\
\text { mastectomizadas }\end{array}$} & \multicolumn{5}{|c|}{ Mulheres Mastectomizadas } \\
\hline & 1 & 2 & 3 & 1 & 2 & 3 & 1 & 2 & 3 & 4 & 5 \\
\hline Idade & $\begin{array}{l}\mathrm{H}: 64 \\
\mathrm{M}: 56\end{array}$ & $\begin{array}{l}\mathrm{H}: 36 \\
\text { M: } 36\end{array}$ & $\begin{array}{l}\mathrm{H}: 47 \\
\text { M: } 39\end{array}$ & 46 & 59 & 39 & 45 & 39 & 64 & 47 & 45 \\
\hline Tempo de União & $\begin{array}{c}38 \\
\text { anos }\end{array}$ & $\begin{array}{c}14 \\
\text { anos }\end{array}$ & $\begin{array}{c}22 \\
\text { anos }\end{array}$ & $\begin{array}{c}18 \\
\text { anos }\end{array}$ & $\begin{array}{c}39 \\
\text { anos }\end{array}$ & $\begin{array}{c}15 \\
\text { anos }\end{array}$ & $\begin{array}{c}28 \\
\text { anos }\end{array}$ & $*$ & $\begin{array}{c}20 \\
\text { anos }\end{array}$ & $*$ & $*$ \\
\hline
\end{tabular}

*Dado não mencionado. 
que realmente estava acontecendo quando receberam o diagnóstico, pois as informações fornecidas pelos profissionais de saúde foram insuficientes e relacionadas apenas à possibilidade cirúrgica de tratamento.

Já para os homens, a maior preocupação advinda do diagnóstico estava relacionada às dificuldades financeiras devido ao alto custo associado à doença e ao medo de ver a companheira com dor.

O mais difícil né, foi a gente né, descobrir esse câncer aí, comprar medicamento caro, entendeu? Sem trabalhar, que eu não tava podendo na hora sabe. Mas, graças a Deus, a gente deu um jeito e resolvemos o problema dela. (Homem do Casal 2)

Difícil demais, foi uma tristeza grande. (Homem do Casal 1)

Abalado. Ah...uma triste. Nóis chorava muito. (Homem do Casal 3)

O momento mais difícil foi agora... Porque passou para os ossos. Eu acho que isso foi mais difícil do que quando descobriu. Quando descobriu foi ruim, mas é que ela ta sentindo muita dor... (CHORO)... ela grita de dor né! (Homem do Casal 3)

Sentimentos de impotência, desesperança, intranquilidade e medo de perderem as esposas são comuns aos companheiros das mulheres ao receberem o diagnóstico do câncer de mama $^{(5)}$. Há, também, a preocupação com o tratamento e condições econômicas para realizá-lo ${ }^{(12)}$.

\section{Impacto da retirada do órgão (mama)}

Diante de tal situação, houve um consenso entre os homens, os quais verbalizaram que não houve alterações com a retirada da mama, visto que o importante era a manutenção da vida da companheira, tal como se observa nas falas de João, Pedro e Vinícius. Importante destacar que não foi encontrado na literatura abordagem sobre a percepção do companheiro frente à retirada da mama.

Não... é esposa do mesmo jeito, é a mesma coisa... pra mim não vai ter diferença, né! Eu sei que falta, mas pra mim não vai ter diferença, é esposa do mesmo jeito. (Homem do Casal 1)

Não, normal! Normal, porque que o seio eu acho não é tudo, o que importante mais da gente é a vida, né. Porque se eu gosto dela, eu não gosto dela só um pedaço, não é o seio que vai fazer eu desgostar dela, eu gosto dela por inteiro, né. Então em caso dela tirar um seio, se fosse os dois, o importante é a vida, é a saúde dela em primeiro lugar. (Homem do Casal 2)

Encarei com muita naturalidade, porque se tinha que tirar, tinha que tirar né! Eu quero ver o bem estar dela, a saúde, ficar boa. (Homem do Casal 3)
Já para as mulheres, os sentimentos mais freqüentes inerentes a esse momento foram de mutilação, constrangimento e preconceito:

Mudou foi muita coisa. Não tenho ânimo de sair... Ah não, parece que todo mundo ta me olhando, me encarando... eu não gosto. A minha vizinha. Ela conversava muito comigo, depois que aconteceu tudo isso comigo, ela não fala mais comigo. Ah todo mundo dali da rua. Ficou todo mundo estranho. Não to saindo assim pra divertir mais não, fico mais em casa. (Mulher do Casal 2)

Retirar minha mama foi mais difícil do que receber a notícia que eu tava com câncer. Porque sim... (MUITO CHORO), sinto que tirou uma coisa muito importante. (Mulher do Casal 2)

... Até então você tava perfeitinha e de repente você ta com a metade, então é muito difícil, foi muito ruim, muito difícil! (Mulher 1)

A retirada da mama freqüentemente gera uma repercussão negativa para a mulher, principalmente no que se refere à sua autoimagem corporal, implicando também em comportamentos de isolamento devido à tristeza pela mutilação, vergonha e receio do preconceito das outras pessoas, quanto à retirada do órgão ${ }^{(7,11)}$. A mama simboliza a feminilidade da mulher e é cheio de representações para a mulher, pois além de ser objeto de desejo e satisfação sexual, também é caracterizado como um dos primeiros laços de estreitamento mãe e filho, e independente da faixa etária na qual a mulher se encontra, quando desenvolve o câncer, ocorre o conflito emocional entre o real e o simbólico ${ }^{(6,12)}$.

É muito comum serem despertados sentimentos de medo de rejeição social e por parte do companheiro ${ }^{(7)}$. Na amostra de mulheres entrevistadas, não foi possível identificar o temor perante possível rejeição do marido, mas observou-se nitidamente o constrangimento relacionado à retirada do órgão e o preconceito referido pelas mulheres mastectomizadas. $\mathrm{O}$ comportamento social das mulheres com câncer de mama é afetado após a mastectomia, provocando restrições na vida social, pois tendem a deixar seus empregos, restringir suas atividades domésticas e sociais, fatos que contribuem para acelerar o comportamento depressivo e o isolamento social, uma vez que passam a se sentir inúteis ${ }^{(15)}$. Entretanto, com o passar do tempo, as mulheres passam a assimilar as consequências da cirurgia e aprendem a conviver com a falta da mama, bem como lutam para aceitar o corpo mutilado e para se readaptar à nova condição(13).

\section{Impacto de outras perdas relacionadas ao câncer}

Além da perda da mama, ou de parte dela, os tratamentos complementares podem determinar outras perdas de cunho físico, tais como a perda dos cabelos, a parada ou irregularidade da menstruação e a infertilidade, o que pode tornar o sentimento de identidade da mulher ainda mais vulnerável $^{(12)}$. A mastectomia costuma causar impacto à mulher, pois 
abala a sua autoestima, uma vez que infringe diretamente sua imagem corporal. Porém, quando associada à quimioterapia, esse impacto pode ainda aumentar em função dos efeitos colaterais associado aos antineoplásicos, como a alopécia ${ }^{(17)}$. Percebeu-se na amostra em estudo que, quando os homens foram questionados a respeito das demais perdas associadas ao câncer de mama, de modo geral todos relataram que a maior delas estava relacionada ao cabelo e que tal aspecto envolvia a perda da beleza feminina. As mulheres por sua vez deram também ênfase à queda do cabelo como o momento mais significativo de perda, mas também ressaltaram a impossibilidade de continuar trabalhando e a perda da vaidade, conforme se observa nas falas a seguir.

... A perda do cabelo, mas é normal também. Isso pra ela é um pouquinho chato porque a mulher sempre tem a beleza dela, né, nunca quer que aconteça o pior com ela. (Homem do Casal 2)

... Eu não posso mais fazer o que eu fazia: trabalhar, ajudar meu marido em casa, eu não posso mais, ajudar até mesmo meus próprios filhos em casa eu não posso. Eu não uso batom mais, você ta vendo aqui... nem batom, nem lápis, eu gostava muito dessas coisas... maquiagem. (Mulher do Casal 3)

Quando começou a cair meu cabelo, eu fiquei desesperada, danei a chorar. Eu chorava constantemente, mas quando caía... meu cabelo era bem cumpridão. (Mulher 3)

Não é pra trabalhar mais, pelo menos por enquanto né, num guento, sinto muita dor, não sou mais a mesma, até um namorado que eu tinha, mandei ele embora, sinto vergonha, tenho vergonha. (Mulher 4)

Tudo, perdeu o cabelo e em geral, porque se fosse só da cabeça seria jóia né. (Mulher 5)

A perda do cabelo traz um forte impacto reacional na muIher porque também afeta a sexualidade ${ }^{(11)}$. A alopécia pode trazer maior sofrimento do que a própria mastectomia já que, no contexto social, a perda do cabelo mostra o diferente, o não belo, a pessoa inquestionavelmente adoecida ${ }^{(7)}$.

A interrupção das atividades também pode gerar sentimentos negativos, uma vez que a mulher se sentirá dependente de outra pessoa, tanto financeiramente como na realização de atividades rotineiras ${ }^{(17)}$. Diante das limitações físicas a mulher também passa a enfrentar as limitações sociais, tais como impossibilidade de desempenhar o trabalho tal como antes, além de delegar o cuidado com os filhos e a casa ${ }^{(15)}$. Ressaltam ainda que as relações pessoais e de amizade também são comprometidas, e em algumas situações instala-se um isolamento social.

\section{Apoio conjugal: visão feminina $x$ visão masculina}

Um dos fatores de grande relevância para o enfrentamento do câncer de mama feminino é o apoio conjugal, uma vez que o apoio fornecido pelo marido para a sua companheira é algo que faz com que a vivência com o câncer seja menos traumática para a mulher que passa por tal situação. Diante disto, ela encontra no marido um aliado e um ponto de equilíbrio e quando esse apoio não ocorre, a mulher se sente mais fragilizada e sem a base sólida que espera do relacionamento conjugal.

A doença traz uma rica oportunidade de se reavaliar sentimentos e posturas dentro da relação conjugal, e a recuperação da mulher fica condicionada a forma como o companheiro aceita a situação ${ }^{(1)}$. Torna-se evidente a importância do apoio do parceiro de forma integral para a recuperação da mulher neste momento de enfrentamento da doença.

Os homens que participaram deste estudo referem ter oferecido um apoio incondicional para as companheiras, independente da etapa da patologia, referindo ainda a tentativa de elevar a auto-estima da parceira.

Os momentos que ela tava mais triste assim, eu tentei reanimar e alegrar ela, né, fazer por onde ela não perceber que isso... na verdade eu faço de tudo pra ela sentir que não ta doente na verdade. Faz de conta que essa doença é uma... uma coisa que acontece na vida da gente. Mas... normal! (Homem do Casal 2)

Na realidade na época eu tava até separado dela, quando eu fiquei sabendo que ela tava com esse problema, eu resolvi... fui atrás dela, tentei até conseguir trazer ela pra casa de volta. Eu não ia deixar ela sozinha, sem ajuda de ninguém. Ai tamo ai até hoje... ela vai fazer radioterapia agora, já terminou a quimio, vai fazer a radioterapia. Eu to do lado dela até o fim. (Homem do Casal 3)

Vou continuar sempre do lado dela. Até o dia da minha morte. (Homem 2)

O cônjuge tem um papel fundamental durante todas as fases do tratamento, existe a necessidade da mulher em contar com o apoio do companheiro durante a fase de reabilitação que ocorre após o diagnóstico e a mastectomia(1). É comum que alguns companheiros de mastectomizadas lhes dêem apoio, não manifestando desconforto com a falta da mama ou mesmo em manter as relações sexuais ${ }^{(7)}$. Entretanto, alguns se afastam das mulheres a partir do diagnóstico do câncer de mama.

Neste estudo, a maioria $(n=6)$ das mulheres confirmou ter recebido amparo do esposo, porém uma delas refutou tal apoio abandonando o companheiro e outra foi abandonada pelo mesmo após o diagnóstico da doença.

... até pra vim fazer quimioterapia e radioterapia, meu marido me acompanhou. (Mulher 2)

Não sou mais a mesma, até um companheiro que eu tinha, mandei ele embora, sinto vergonha, tenho vergonha. (Mulher 4)

Quando ele descobriu, ele pediu logo pra separar, que eu acho que seria o querer maior dele né, porque é quando a 
gente precisa.. E você vê eu fui tão forte, mas tão forte que veio a doença, cirurgia, perda de emprego, de tudo né, da saúde e aí veio pra me separar dele e eu dei assim de mão, graças a Deus. Eu sou muito forte, eu sou guerreira, minha fia, eu tenho orgulho de mim. (Mulher 5)

Talvez seja difícil manter um relacionamento em uma situação de temor e sofrimento que muitas vezes é imposta pela mastectomia, que requer reestruturação relacional, familiar, paciência e dedicação frente a uma sociedade que valoriza a estética ${ }^{(1)}$. A reação do parceiro está diretamente associada ao restabelecimento, à recuperação da identidade corporal e sexual.

A importância do apoio à mulher com câncer de mama pode ser observada em estudo em que se verificou que muIheres com companheiro apresentaram melhora nas suas emoções e no relacionamento interpessoal, em relação a mulheres que não tinham um relacionamento estável e que, com a mastectomia, sentiam-se inferiorizadas, se comparadas àquelas que possuem mamas e que não realizaram procedimento cirúrgico, e também acreditam ser menos capazes de estabelecer novos vínculos afetivos ${ }^{(14)}$. Além disso, observou-se que mulheres que não possuem companheiros parecem ser mais frágeis face às mudanças que ocorrem em sua vida cotidiana, principalmente no que diz respeito aos relacionamentos afetuosos ${ }^{(14)}$.

\section{REPERCUSSÕES NA VIDA COTIDIANA}

\section{Apoio familiar}

Considerando que diante de uma doença como o câncer de mama a mulher fica extremamente fragilizada, é neste instante que a família assume seu papel de proteção e amparo, ajudando-a a superar os momentos em que ela se sente impotente e incapaz. Constatando tal afirmação, todas as mulheres que fizeram parte da amostra referiram ter recebido apoio familiar constante por parte de diferentes membros da família e alegaram ainda que se sentiram mais cuidadas, recebendo excesso de carinho e atenção em comparação ao período pré câncer.

... Minha sorte foi meus filhos que me dá muita força, minha nora. Meu filho faz 4 anos que ta com uma moça, uma menina, lá, ai eu gosto muito dela, mesmo que uma filha pra mim, ai a gente se dá muito bem. Na noite que eu me operei, ela foi quem passou as duas noites comigo, a minha nora. Minha filha não deixa eu fazer nada. (Mulher do Casal 1)

Eu tenho duas filhas, uma é bióloga e outra é historiadora e todas duas também me apoiaram muito também. A minha mãe que já faleceu, também. Então quer dizer, eu tive apoio total da família, foi muito bom, realmente essa parte eu acho até assim, dobraram em excesso os cuidados, os carinhos, entendeu? (Mulher 1)

Encontrei força numa criança de 10 anos e outro de 8 anos... São meus filhos. Foram meus dois companheiros de quimioterapia. Eles vinham junto comigo, um pegava na minha mão, o outro pegava na outra e falava: 'Vamos mãe, coragem mãe, que a senhora vai conseguir.' (CHORO) E olha que é porque eu tenho uma moça de 19 anos e um rapaz. E aonde eu encontrei mais apoio foi nessas duas crianças. (Mulher 2)

Geralmente, a confirmação do diagnóstico causa impacto psicossocial, tanto na paciente quanto em seus familiares, por isso, requer uma rede social de apoio que viabilize o reconhecimento e a aceitação da doença, para que a mulher possa encontrar a melhor forma de adaptação ${ }^{(13,15)}$. Normalmente, a família ocupa esse lugar ${ }^{(6)}$.

Apesar de tais afirmações, existe a possibilidade da dinâmica familiar ser alterada, pois muitas vezes a mulher tem dificuldade de retomar à sua vida pessoal e também social ${ }^{(6)}$. Além disso, a experiência de conviver com uma mulher com câncer de mama pode ser considerada como fator de sobrecarga física e emocional para a família, uma vez que os cuidados prestados podem levar a mudanças na dinâmica e estruturas familiares, sendo potencial fonte de estresse ${ }^{(18)}$.

\section{A busca da espiritualidade como uma estratégia de enfrentamento}

As pessoas, de um modo geral, possuem a tendência de buscar respostas para os acontecimentos da vida em algo divino, num ser maior e mais poderoso que é Deus. Dessa forma elas se sentem mais amparadas e confortadas. Percebe-se nas falas dos participantes do estudo que para os homens, a fé em Deus funciona como um forte suporte emocional para vivenciar essa situação. Já para as mulheres, além de ser um suporte em diferentes momentos, o poder divino é também responsável pela única possibilidade de cura.

Se Deus não tiver no controle, nada vai acontecer. Se Deus não tiver no controle, não adianta a gente falar: Ah, eu vou ficar curada, não adianta. Eles fazem a parte dele, só, mas quem manda é o Senhor! (Mulher 1)

A busca religiosa em pacientes com câncer não deve ser entendida como uma forma de fuga da realidade, mas como uma possibilidade de vislumbrar um futuro apesar do sofrimento causado pela doença, ou ainda uma ajuda no processo de cura e de aceitação da doença, uma vez que há a disponibilidade de outras formas de construção de sentidos para a doença o que possibilita ao doente e aos seus familiares, um maior empoderamento para vivenciarem essa experiência ${ }^{(5)}$.

\section{Auto-percepção após a mastectomia}

A doença provoca uma série de mudanças na vida das muIheres, interferindo no sentimento em relação a si mesmo e na percepção da vida, geralmente relacionadas com insatisfação e não aceitação da perda da mama ${ }^{(1)}$. Emergem sentimentos contraditórios de esperança na cura e medo de recidiva, de enfrentar a mutilação imposta pela mastectomia, associadas a preocupações com a feminilidade e com as reações do companheiro frente à mastectomia, o que pode acarretar em uma baixa auto-estima ${ }^{(11)}$. 
Frente a essa questão, as mulheres citadas no estudo referem que após vivenciarem etapas dolorosas e modificadoras da doença, tanto no aspecto físico como no psicológico, as mesmas desenvolveram falta de ânimo para desempenhar atividades que antes eram tidas como normais, devido às limitações e alterações em sua auto-imagem proveniente da mastectomia.

Ai ai eu sou diferente agora. Sei lá, nem sei explicar! Não, assim tratar as pessoas eu trato bem. Agora assim pra sair é que eu não animo mais de sair. (Mulher do Casal 2)

Porém, há também a evidencia de que a doença tenha refletido em mudanças saudáveis no hábito de vida dessas muIheres, conforme visualizado na fala de Julia. Dessa forma, a mulher se depara com a necessidade de encarar a vida de uma nova maneira, visto que a doença traz alterações para toda a vida, fazendo com que a mesma aprenda a lidar com novas situações, restrições e possíveis barreiras.

Eu vou falar... eu gostava de beber uma cervejinha, eu gostava de dançar forró, eu fazia muito essas coisas e agora não. Mas eu acho que mudou pra melhor, porque isso só me atrapalhava. Eu fumava, então quer dizer só mudou pra melhor né. Sobre isso ai eu não me queixo muito não. (Mulher do Casal 3)

Tais achados corroboram com alguns autores ${ }^{(15,13)}$ quando referem que o processo de adoecer leva a mulher a uma valorização da vida e do auto-cuidado, permanecendo conscientes da realidade de recorrência.

\section{Sexualidade do casal}

Atualmente, a sociedade considera a sexualidade como a única forma de manter uma relação estável e sólida. Quando algo, como uma doença como o câncer de mama juntamente com a realização da mastectomia, impõe a possibilidade desse ato ser interrompido, a relação conjugal é abalada e muitas vezes se configura em motivo de separação. Tal fato ocorre porque muitas mulheres sentem vergonha do próprio corpo ou temem que o marido perca a atração por sua companheira. Porém, nem sempre a perda da sexualidade implica necessariamente na perda do amor e companheirismo por parte do casal.

Confirmando tais inferências, observou-se que para a maioria dos homens $(n=5)$ não houve alteração da sexualidade, tendo ainda relatos de ter intensificado a relação. No entanto, um deles afirmou que a intimidade do casal foi prejudicada em decorrência da doença.

... Pra mim ela continuou linda do mesmo jeito. Com certeza, pra mim ta melhor. Sempre, sempre... sem nenhum preconceito. (Homem do Casal 3)

Não... mudou assim algumas partes. Ah coisas íntimas mudou né. Quando ela começou a tomar a quimio, você sabe que a pessoa fica fraca né...de qualquer jeito pode mudar alguma coisa. (Homem 3)

Exercer a sexualidade de forma plena e sentir-se atraente é fundamental para a mulher e interfere, inclusive, em sua qualidade de vida $^{(14)}$. Para tanto, exige intimidade, respeito e comunicação. Neste estudo, as mulheres reiteram a fala dos homens no que concerne à ausência de alterações, porém Alice e Júlia relataram que embora não tenham ocorrido mudanças na sexualidade por parte do marido, elas perceberam que houve mudanças em sua sexualidade.

Eu não sei se é devido o nervoso ou outra coisa... é até vergonha de eu falar isso, ele vem me procurar, né, e eu não tenho mais sensação pra nada... (Mulher do Casal 1)

Não, por ele não, mas por mim sim por causa do tratamento né, por que... Não por ele não, só por mim mesmo! Por mim assim, eu acho que eu fiquei mais... fria, no caso né, mais... sem amor. (Mulher do Casal 3)

Ainda que existisse uma vida sexual ativa antes do diagnóstico do câncer de mama, a doença traz consigo implicações que vão desorganizar o funcionamento sexual do casal, tais como comprometimento da autoimagem corporal, dor, fadiga, não só pelo impacto do diagnóstico, mas, também, pelos efeitos adversos relacionados ao tratamento ${ }^{(1)}$. Especificamente, em relação ao tratamento, ocorre menopausa precoce, diminuição da libido e alteração na produção de hormônios sexuais, o que torna o ato sexual doloroso, além de diminuir a excitação e inibir o orgasmo ${ }^{(12)}$.

\section{CONCLUSÃO}

Partindo do pressuposto de que o câncer de mama é uma enfermidade que tem caráter de risco para a vida da mulher, seja de forma psíquica ou física, vale salientar que a família também é diretamente afetada por essa enfermidade, pois é ela que está em constante contato com a paciente. Dessa forma, visando obter uma análise mais abrangente sobre o assunto, objetivou-se identificar como casais enfrentam essa doença; quais foram as barreiras que os mesmos encontraram e de que forma essa doença repercutiu em suas vidas.

Observa-se que, na literatura, há um déficit de estudos que abordam o impacto do câncer de mama na vida dos casais, visto que, na maioria dos estudos, a única preocupação é conhecer as repercussões existentes na vida da mulher, deixando de lado a opinião e reação do companheiro que se depara e vivencia com todos os estágios da doença.

Neste estudo, foi possível notar que a maneira como o homem vê o câncer é muito similar à forma com que a mulher o vivencia, passando por estágios que vão desde a aceitação, o pavor do recebimento da notícia e o medo das possíveis conseqüências advindas desse diagnóstico. Portanto, torna-se necessário a elaboração de novos estudos sobre o impacto do diagnóstico do câncer de mama na vida dos casais, para possibilitar a realização de uma assistência mais humanizada e centrada nas dificuldades especificas dos casais. 
É perceptível que as repercussões advindas do diagnóstico da doença para as mulheres são, em sua maioria, vivenciadas de forma negativa, pois é um momento de intenso sofrimento para elas, que se deparam com a eminência de morte, seguida pelo pavor de ser tornarem dependentes. Além disso, a realização da mastectomia, que surge em seguida, fragiliza ainda mais essa mulher que vê sua feminilidade sendo afetada e em muitas vezes de uma forma irreversível. E para contemplar esses momentos de perda e fragilidade, a queda do cabelo surge para interromper por completo com a identidade feminina da mulher e conseqüentemente com sua vaidade, pois ela se sente inferior e feia em relação às outras pessoas.

Os homens, por sua vez, ao se depararem com a enfermidade de suas companheiras, sentem pavor em perdê-las e medo de presenciar o sofrimento delas, por meio da dor. Portanto, nota-se que as preocupações dos homens se voltam para todas as necessidades das mulheres, pois os mesmos sentem a necessidade de demonstrar um apoio constante a elas e acabam exercendo um papel de cuidador, parceiro e confidente. Contudo, o apoio conjugal é extremante importante para o enfrentamento da doença, pois dessa forma tanto a mulher quanto o homem, podem se ajudar nos momentos de fraqueza, fazendo com que a vivencia da enfermidade seja amenizada.

Além de todos os aspectos já mencionados, outro ponto que nos leva a reflexão é a maneira como devem ser fornecidas as informações a respeito da saúde/doença de um paciente, pois é um momento em que o indivíduo encontra-se debilitado e impotente. Portanto, a forma como o profissional de saúde vai passar determinadas notícias ao paciente, pode implicar em como a pessoa vai se portar durante o tratamento. Deve haver um maior preparo por parte dos profissionais no sentido de analisar o caso e identificar a melhor maneira de transmitir essas informações, cabendo a eles buscarem estratégias de amenizar a situação e fornecer ainda apoio e companheirismo ao paciente.

O surgimento do câncer de mama na vida do casal é algo que modifica a vida dessas pessoas para sempre. A gama de dificuldades que os mesmos enfrentam é extensa e traumática, porém se os dois se mantiverem unidos, o enfrentamento dessa doença é facilitado, uma vez que o suporte emocional dado de um para o outro auxilia em todos os períodos da doença. É necessário saber respeitar o limite de cada um, sem colocar imposições, apenas deixando claro que independente da situação esse apoio será fornecido e fortalecido.

Para que o impacto de ter câncer de mama seja vivenciado de uma forma mais amena é necessário que a sociedade seja informada quanto aos cuidados prévios para a prevenção e formas de enfrentamento caso alguém se depare com tal situação com um familiar ou consigo mesma, fazendo com esta doença na vida de determinada pessoa não tenha um efeito extremamente traumático, conforme visualizado neste estudo.

\section{REFERÊNCIAS}

1. Talhaferro B, Lemos SS, Oliveira E. Mastectomia e suas conseqüências na vida da mulher. Arq.Ciênc. Saúde 2007; 14(1): 17-22.

2. Brasil, Ministério da Saúde. Sistema de Informação do Controle do Câncer de Mama (SISMAMA), 2008. [Citado em: 13 out 2009]. Disponível em: http://www.saude. sc.gov.br/geral/planos/programas_e_projetos/saude_muIher/sismama/sismama.htm.

3. Makluf ASD, Dias RC, Barra AA. Avaliação da qualidade de vida em mulheres com câncer da mama. Revista Brasileira de Cancerologia 2006; 52(1): 49-58.

4. Venâncio JL. Importância da atuação do psicólogo no Tratamento de Mulheres com Câncer de Mama. Revista Brasileira de Cancerologia 2004; 50(1): 55-63.

5. Ferreira CB, Almeida AM, Rasera EF. Sentimentos do diagnóstico por câncer de mama feminino para casais que o vivenciaram. Interface - Comunicação, Saúde e Educação 2008; 12(27): 863-871.

6. Vieira CP, Lopes MHBM, Shimo AKK. Sentimentos e experiências na vida das mulheres com câncer de mama. Rev Esc Enferm USP 2007; 41(2): 311-316.

7. Pereira SG, Rosenhein DP, Bulhosa MS, Lunardi VL, Filho WDL. Vivências de cuidados da mulher mastectomizada: uma pesquisa bibliográfica. Rev Bras Enferm 2006; 59(6): 791-795.
8. Bogdan RC.; Biklen SK. Investigação qualitativa em educação: uma introdução à teoria a aos métodos. Lisboa: Porto Editora; 2006.

9. Bardin L. Análise de conteúdo. Lisboa: Edições Setenta; 2004.

10. Brasil, Ministério da Saúde. Conselho Nacional de Saúde. Diretrizes e Normas Regulamentadoras de Pesquisa Envolvendo Seres Humanos. Resolução 196 de 1996. Informes Epidemiológicos do SUS, v.5, n.2, abr.-jun, 1996. Suplemento 3. p.14-41.

11. Fabbro MRC, Montrone AVG, Santos S. Percepções, conhecimentos e vivências de mulheres com câncer de mama. Rev. Enferm-UERJ 2008; 16(4): 532-537.

12. Silva LC. Câncer de Mama e sofrimento psicológico: aspectos relacionados ao feminino. Revista Psicologia em Estudo 2008; 13(2):231-237.

13. Caetano EA, Gradim CVC, Santos LES. Câncer de mama: reações e enfrentamento ao receber o diagnóstico. Revista de Enfermagem UERJ 2009; 17(2): 257-261.

14. Huguet PR, Morais SS, Osis MJD, Neto AMP, Gurgel MSC. Qualidade de vida e sexualidade de mulheres tratadas de câncer de mama. Revista Brasileira de Ginecologia Obstétrica 2009; 31(2): 61-67.

15. Araújo LMA, Fernandes AFC. O significado do diagnóstico do câncer de mama para a mulher. Esc. Anna Nery 
Revista de Enfermagem 2008; 12(4): 664-671.

16. Ferreira CB, Almeida AM, Rasera EF. Sentimentos do diagnóstico por câncer de mama feminino para casais que o vivenciaram. Interface - Comunicação, Saúde e Educação 2008; 12(27): 863-871.

17. Melo EM, Araujo TL, Oliveira TC, Almeida DT. Mulher mastectomizada em tratamento quimioterápico: um estudo dos comportamentos na perspectiva do modelo adaptativo de Roy. Revista Brasileira de Cancerologia 2002; 48(1): 21-28.

18. Tavares JSC, Trad LAB. Famílias de mulheres com câncer de mama: Desafios associados com o cuidado e os fatores de enfrentamento. Interface - Comunicação, Saúde e Educação 2009; 13(29): 395-408. 